\title{
A imagem como uma possibilidade de sensibilização na Educação
}

Terezinha Oliveira

Sandra Regina Franchi Rubim

Universidade Estadual de Maringá

\section{Resumo}

Analisaremos, neste artigo, o uso da imagem como recurso educativo à sensibilização humana. Nós nos fundamentaremos em Hegel, em Aumont e Morin. Nossa construção teórico-metodológica será tecida com os fios da história social, pois ela nos permite compreender que as relações sociais constituem o fundamento da expressão artística. Por considerar a arte como parte constitutiva do fazer humano na sua totalidade - 0 sensível, o ético e o cognitivo-, observamos que a análise de imagens artísticas tornam o olhar da pessoa mais atento às representações e aos seus significados. É, pois, por acreditarmos que a imagem pode sensibilizar e possibilitar a conscientização do sujeito que a apontamos como fonte para a História e a História da Educação.

Palavras-chave: Imagem. Sensibilidade. História da Educação. 


\section{Images as a possibility for sensitizing in education}

This paper examines the use of images as an educational resource towards human awareness, and is based on Hegel, Amount and Morin. Our theoretical-methodological construction touches on social history, which helps us to understand that social relations constitute the foundation of artistic expression. While considering art as a constituent part of the totality of human actions - the sensitive, ethical and cognitive aspects - we observed that the analysis of artistic images makes people look more attentively at representations and their meanings. As a source of analysis in History and History of Education, images can sensitize and enable awareness in people.

Keywords: Images. Sensitivity. History of Education.

\section{La imagen como una posibilidad de sensibilización en educación}

Analizaremos, en este artículo, el uso de la imagen como recurso educativo importante a la sensibilización humana. Nos fundamentaremos en Hegel, en Aumont y Morin. Nuestra construcción teórico-metodológica será tejida con los hilos de la historia social, pues ella nos permite comprender que las relaciones sociales constituyen el fundamento de la expresión artística. Por considerar el arte como parte constitutiva del quehacer humano en su totalidad - en lo sensible, lo ético y lo cognitivo-, observamos que el análisis de imágenes artísticas tornan la mirada de la persona más atenta a las representaciones y a sus significados. Es, pues, por creer que la imagen puede sensibilizar y posibilitar la concienciación del sujeto, que la apuntamos como fuente para la Historia y la historia de la Educación..

Palabras clave: Imagen. Sensibilidad. Historia de la Educación. 


\section{Introdução}

Com a expansão do capitalismo no Ocidente, em fins do século XIX, constata-se a coligação de, em uma mesma teia de relações, povos diversos cujas especificidades observam-se nos diversos idiomas e formas peculiares de escrita. As transações comerciais e a industrialização aproximaram regiões, transpuseram oceanos e promoveram uma constante mobilidade de pessoas de um ponto a outro do planeta. Nesse panorama, nota-se que a revolução no conhecimento se concentrou não na escrita, mas no registro, reprodução e difusão de sons e imagens. A rapidez com a qual processamos informações visuais constitui um forte argumento em favor do uso das imagens na comunicação social.

Vivemos em um mundo repleto de outdoors, de placas luminosas, de sons e imagens diversas. Nesse cenário, as imagens encantam-nos, seduzem ou passam despercebidas. A imagem, como uma linguagem visual universal, constitui-se em uma forma de entendimento afetivo do mundo. Nesse contexto, percebemos a circulação de pessoas, produtos e, principalmente, imagens, as quais nos transmitem, de forma explícita ou implícita, diversas informações e mensagens. Como temos que conviver, diariamente, com essa produção infinita, necessitamos aprender a avaliar essa cultura visual, sua função, sua forma e seu conteúdo, pois a criação e a apreciação da arte possibilitam e privilegiam o aperfeiçoamento da sensibilidade do ser humano, contribuindo, por sua vez, para a sua civilidade. Assim, por meio da arte, poderemos compreender as transformações que ocorrem em nosso tempo histórico. As criações artísticas precisam ser fruídas, despertando os sentidos da sutileza, da sensibilidade estética, do belo, do conhecimento e da visão crítica de mundo.

Nesse sentido, confirma Francastel (1993, p. 48): “Apreciaremos melhor a arte do passado e a do presente se lhe conhecermos melhor a significação humana [...] nossa sensibilidade estética só pode se refinar pelo estudo". A apreciação e a análise de imagens, por meio do conhecimento e da sensibilidade, tornam possível identificar as posições éticas, estéticas e políticas que o indivíduo, como autor da obra, assume diante das lutas históricas do presente em que vive como aprovação ou negação, que são as formas de se relacionar com o mundo (Peixoto, 2001). Com efeito, entendemos que a capacidade intelectiva humana nos dá a probabilidade, como potência de ação, de deixarmos a posição de observadores passivos para ocupar a de expectadores partícipes e críticos diante da leitura de textos, imagens, cidades, rostos, gestos, cenas, pinturas, entre outros.

Para alcançar esse objetivo, entretanto, é fundamental que o ser humano, enquanto sujeito de conhecimento histórico, estabeleça contato com diferentes produções de épocas passadas e atuais, observando e identificando informações nas mais diversas 
formas de linguagem. Esses procedimentos oferecem ao ser humano a possibilidade de ampliar o seu olhar, questionar as fronteiras disciplinares e articular os saberes (Fonseca, 2006). É relevante considerar a multiplicidade de significados dos símbolos e sinais culturais, bem como da contextualização social e da dinâmica histórica daí resultante. Esse procedimento nos oferece oportunidades para investigar e produzir conhecimentos acerca da realidade, para estabelecer relações críticas e para nos expressarmos nas nossas relações sociais cotidianas, enquanto sujeitos produtores de história e de saber.

A nosso ver, a apreciação e análise de imagens artísticas direcionam o olhar das pessoas, tornando-as mais atentas às representações e aos seus significados e, em consequência, mais conscientes de sua realidade histórica e social. Consideramos, nesse sentido, que as imagens representam um importante elemento da atividade sociocultural, principalmente por constituir um sistema de significações específicas que permite a reflexão, ação e expressão do ser humano em relação a si próprio, aos demais indivíduos e ao meio em que vive. Dessa forma, teremos condições de nos posicionar com firmeza e autonomia intelectual diante dos problemas cotidianos.

A complexidade do mundo contemporâneo exige dos sujeitos sentimentos, conhecimentos e sensibilidade para pensarem e agirem diante de situações novas. Sob este aspecto, o princípio norteador de qualquer trabalho artístico seria a possibilidade de todas as artes contribuírem para a arte de viver. É nessa perspectiva que desenvolvemos nosso trabalho. Entendemos que a arte, como linguagem humana, acompanha as mudanças históricas e, consequentemente, a forma de viver em sociedade. Temos, assim, como finalidade geral, neste artigo, abalizar a necessidade de a Educação adentrar no campo das imagens. A maneira pela qual a arte se direciona para a sensibilidade oportuniza a materialização das experiências reais, permitindo, então, a abertura da sensibilidade para os fatos exteriores ao indivíduo.

Nesses termos, tendo em vista a complexidade das relações sociais nos tempos atuais e a necessidade de abordar o ser humano nas dimensões afetiva, cognitiva e social, adotamos como método de pesquisa o da História Social. Isso porque o objeto próprio dos estudos históricos é o ser humano em sociedade, o sujeito histórico.

Castro (1997, p. 54) caracteriza a História Social “[...] enquanto forma de abordagem que prioriza a experiência humana e os processos de diferenciação e individuação dos comportamentos e identidades coletivos - sociais - na explicação histórica". Não é o ser humano isolado em um único instante que importa, mas sim o ser humano e as relações sociais, bem como seus modos de sentir e pensar. Esse pensamento faz com que a história social seja entendida como um alargamento do interesse histórico, pois todas as abordagens perpassam pelo social e se interligam. 
Postulamos, assim, que o conhecimento produzido historicamente, não somente o da Educação ou o da História, mas o da literatura, da poesia, das artes, é indispensável para o processo de sensibilização e educação do ser humano. Esta abordagem é nosso foco nesse artigo. Dessa forma, primeiramente nos atentaremos em explicitar a relação entre arte e educação. Na sequência, discorreremos sobre o caminho histórico da reflexão filosófica em torno da arte, bem como enfatizaremos a importância do conhecimento e da sensibilização para nos aproximarmos dos sentidos dessa linguagem.

\section{A relação da arte com a educação}

Consideramos que uma das razões da História da Educação é entender o processo educativo por meio das ações sociais. Por isso, destacamos que nossa abordagem da linguagem imagética, como já mencionamos, situa-se nos campos da História Social e da História da Educação, os quais têm como uma de suas finalidades a compreensão das origens das instituições, dos conteúdos e dos pensamentos que permeiam a educação contemporânea. Com base em seus fundamentos, definimos nosso olhar para as imagens como possibilidade de nos aproximarmos da compreensão que os sujeitos têm ou tinham do seu tempo e espaço e das relações sociais que caracterizam suas vidas. Acreditamos que cada momento histórico produz uma determinada forma de pensar, correlacionada à maneira como se constrói a existência do ser humano. Assim, o discurso imagético, tal como outras linguagens humanas, escrita ou oral, é construído nas relações sociais. Desse modo, podemos afirmar que, por meio das imagens, constroem-se discursos cujos sentidos difundem-se com uma intenção formativa para uma construção social. Entendemos que a Educação, em todos os períodos da História, procura abrir caminhos que possibilitem novos horizontes para a formação humana.

Nesse sentido, acentuamos que a abordagem educacional em nossa pesquisa está relacionada ao entendimento de que a Educação ocorre e perpassa as relações sociais, como uma exigência de formação do ser humano para a vida em sociedade. Buscamos, dessa forma, captar como os sujeitos realizam ou realizaram suas ações, ou seja, como, em diferentes lugares e momentos, uma determinada realidade é construída, pensada, dada a ler, como são as suas práticas educativas e quais são os objetivos para o desenvolvimento do indivíduo e da sociedade. Desse modo, poderemos retomar lições que nos ensinem a ser, antes de tudo, pessoas envolvidas com as questões do nosso presente, com o bem viver coletivo. Pretendemos apresentar a linguagem imagética em correlação com as construções sociais e educacionais, de forma a instigar leitores 
e leitoras a refletir sobre a importância do tema para a atualidade, uma vez que "[...] uma ciência nos parecerá sempre ter algo de incompleto se não nos ajudar, cedo ou tarde a viver melhor" (Bloch, 2001, p. 45).

Observamos que a imagem tem em si a probabilidade de transmitir a construção de uma interpretação de certo acontecimento e, concomitantemente, a projeção de uma intencionalidade daquele que faz o discurso. Podemos indicar que, em toda linguagem, escrita, falada ou imagética, há uma intenção de ensinar ou de aprender.

A História da Educação oferece-nos oportunidade de se compreender as produções humanas, em especial a arte e a educação, como resultantes das múltiplas vinculações articuladas pela dinâmica social, e não da ação de indivíduos isolados, independentes do contexto que os cerca.

No mundo globalizado que caracteriza a atualidade, verifica-se, em linha ascendente, a perda da criticidade dos indivíduos em relação ao contexto social em que vivem, bem como em relação a referenciais éticos e morais. 0 resultado é um embrutecimento que distancia cada vez mais os seres humanos uns dos outros. Nota-se a falta do engajamento das pessoas em causas que convirjam para o bem viver coletivo, para dar novos sentidos à existência individual. Com base nessa reflexão entendemos que sensibilidade é condição de vida.

Nesse processo, percebemos que a leitura de imagens permite gerar uma nova sensibilidade, difundir novos valores, ideias e comportamentos indispensáveis para o desenvolvimento e a conservação da sociedade, tornando-se um instrumento de educação dos sujeitos. Dessa forma, atribuímos à sensibilidade um papel de destaque ao processo de formação humana.

\section{Imagem como possibilidade de sensibilização e educação do ser humano}

Sabe-se que a imagem artística sempre existiu. Paralelamente a ela, produziu-se um discurso, uma preocupação sobre sua natureza, seus poderes, suas funções. Com o advento do Renascimento, verificou-se uma reflexão filosófica em torno da arte, a qual tinha a apreciação da beleza como tema fundamental. Foi nesse período que ocorreu a união teórica do belo com a arte. Passou-se a valorizar, além do universo material, o sensível. Aumont (1993) destaca que Shaftesbury (1671-1713), pioneiro da estética, já falava que o belo revelava-se, além das impressões visuais e auditivas, por intermédio de uma visão interior. Para ele, a dimensão do belo estava aberta ao espírito por meio da sensibilidade. 0 belo captado por intermédio da visão e da audição era relacionado imediatamente com uma ordem de sentimentos, de emoções. Dessa 
tendência, surge no século XVIII uma nova disciplina filosófica, responsável pelo estudo do belo e suas manifestações na arte. Segundo Aumont (1993) Alexandre Gottlieb Baumgarten (1714-1762), fundador dessa teoria, denominou-a de estética, termo derivado do grego aisthési, o qual estava relacionado com o que é sensível. Em 1750, Baumgarten publica a Aesthetica sive theoria liberalium artium (Estética ou Teoria das Artes Liberais), que conceitua essa disciplina como ciência do belo e da arte.

Cauquelin (2005), por sua vez, adverte-nos da necessidade de precisar o sentido do conceito de estética a ser adotado, pois ele é ambíguo. Sabe-se que foi no século XVIII que se utilizou o termo $A$ estetica, pela primeira vez, como a ciência do sensível, relacionado com a percepção, os sentimentos e a imaginação. Ela salienta, porém, que essa designação da estética vem de longe, desde a Antiguidade. Seus elementos, talvez ainda pouco sólidos, foram preparados no passado, constituindo-se como seu fundo genético antes de ser apresentado nesse século. Aceita-se, pois, que ao século XVIII seja atribuída a gênese da estética como ciência da arte e da arte em uma dimensão autônoma, que permite desvendar nos seres e nas coisas certa inteligibilidade, "[...] na busca da verdade, do bem e do belo, as formas ou idéias que são a fonte e ao mesmo tempo o fim de toda a presença no mundo" (Cauquelin, 2005, p. 31). 0 termo foi proposto, enfim, com o objetivo de abarcar diferentes pesquisas, ensaios, diálogos filosóficos que tinham por objeto as noções de belo, de estilo, de gênero. Primeiramente, restringiu-se ao estudo das sensações e dos sentimentos produzidos pela obra de arte. Rapidamente sofreu mudanças, passando a designar o estudo da fonte das sensações agradáveis concebidas pela obra de arte, ou seja, o belo.

Em relação ao conceito de estética, Hegel (1996) afirma que estética é a filosofia, é a ciência do belo, do belo artístico, que exclui o belo natural. Para ele, o belo artístico é superior ao belo natural, pois o belo artístico é objeto do espírito (superior à natureza); tudo que passa pelo espírito é superior ao natural. Nesse sentido, o autor afirma que “[...] a arte foi para o homem [sic] instrumento de consciencialização das ideias e dos interesses mais nobres do espírito. Foi nas obras artísticas que os povos depuseram concepções mais altas [...]" (Hegel, 1996, p. 5). Do ponto de vista do autor, as diferentes representações pelas quais a arte se efetiva como a pintura, a escultura, a literatura, etc., contribuem e constituem-se no em elemento fundamental à sensibilização dos homens. Ainda de acordo com Hegel, a obra de arte amplia a capacidade de criação do homem porque os torna melhores.

A arte concebida como modo de ação produtiva do ser humano constitui-se como um fenômeno social e parte da cultura. Ela está relacionada com a totalidade da existência humana, conectada com o processo histórico e possui a sua própria história, a que correspondem estilos e formas definidas. Suscita questões de valor tanto na 
esfera coletiva quanto a existência individual, concernentes tanto ao artista que cria a obra de arte quanto ao contemplador que sente seus efeitos. Por fim, mediante a necessidade de apreender e decifrar o sentido de uma obra, torna-se relevante a busca do entendimento do sentido das obras e do trabalho artístico, compreendidos enquanto significação e direção (Cauquelin, 2005).

Verificamos, assim, que, para analisá-la, é preciso conhecimento da especificidade dessa linguagem, de seus avanços e limites. Consideramos, nesse sentido, que:

[...] Interpretar exige paciência, a imagem deve ser olhada, questionada, para que história e memória sejam entendidas. Olhar não é simplesmente ver, nem observar com mais ou menos competência. Ele pressupõe a implicação, delibera uma experiência, isto é, uma explicação. As criações humanas só são suscetíveis de interpretação e de explicação pelo caminho da compreensão implicativa, de uma tomada de consciência sobre si mesmo. Logo, o objeto de conhecimento é reconhecido por estar intimamente em constituição pelo sujeito que conhece. Para tal, ele deve dialogar com a imagem, interrogá-la e estabelecer certa intimidade com a mesma. (Kern, 2007, p.140).

A leitura de imagens explicita a mediação entre a obra e seus espectadores, entre o produtor e o leitor. Consideramos que a ideia da obra é inesgotável, e o seu sentido é produzido pelo trabalho do artista com uma intencionalidade, tornando-o apreensível. Assim, exige-se compreensão, entendimento, significação e conhecimento. Salientamos, porém, que, se nos detivermos na primeira evidência a respeito do sentido da obra, corremos o risco de nos distanciar de sua significação. É preciso ir além do que se vê, romper com a superficialidade do visível e imediato e aprofundar o diálogo sugerido e implícito na obra. A compreensão, que no primeiro momento nos parece espontânea, pode alargar-se mediante o exercício do diálogo, na busca de um entendimento mais completo.

Nesses termos, mencionamos a contribuição de Francastel (1993), a qual acreditamos ser bastante significativa. 0 mundo visual, afirma o autor, não só possui sua lógica própria como ainda funda um modelo particular de atividade produtiva, ou seja, um pensamento plástico ou figurativo. Dessa forma, existem valores e sentidos que somente as imagens possuem; elas transmitem informações para o intelecto com base em regras específicas, experiências, percepções e esquemas representativos do pensamento e, por isso, não são substituídas por outras formas de linguagens.

Assim, além da receptividade emotiva, exige-se do contemplador um desenvolvimento intelectual. Percebe-se a necessidade de se pautar em alguns elementos para, ao apreciar e analisar as imagens, identificar as posições éticas, estéticas e políticas que o indivíduo criador assume quando expressa os embates de seu tempo histórico. 
Com base nesses elementos, o observador pode também identificar a maneira pela qual o artista se relaciona com esse mundo. Nesse propósito,

[...] toda a obra de arte pertence a uma época, a um povo, a um meio, relaciona-se com certas representações e fins, históricos ou não, obrigando o estudioso de arte [a] possuir vastos conhecimentos, simultaneamente históricos e muito especializados, dado que a natureza individual da obra artística contém pormenores particulares e especiais indispensáveis para a sua compreensão e interpretação. (Hegel, 1996, p. 62).

Ao olhar os documentos artísticos sob os aspectos histórico e social, salientamos a impossibilidade de lê-los como simples objetos que expressam contextos. Uma obra de arte pressupõe a existência de sujeitos que expressam sentidos específicos para sua realidade, para seu contexto cultural. Por meio de estilos comuns, de formas, de contornos, das condições materiais e intelectuais da sua época, mas também por meio de sua potencialidade individual, o artista cria novas referências para o universo no qual está inserido. Acrescentamos ainda que, para um leitor contemporâneo, uma obra está impregnada das muitas leituras que já foram realizadas sobre ela. Assim, observase um diálogo entre o indivíduo-criador, em um tempo distante ou não, e o sujeitocontemplador. Nessas condições, o conhecimento é indispensável para evitarmos interpretações singelas sobre aquilo que acreditamos compreender de uma obra, uma vez que ela faz parte de um legado comum, de um mesmo contexto cultural e de um mesmo momento histórico.

Apontamos, então, a necessidade da Educação adentrar no campo das imagens e das linguagens tecnológicas. Torna-se crucial desenvolver a sensibilidade humana, ampliando, assim, a dimensão da reflexão. Acreditamos que esses requisitos podem ser desenvolvidos por meio da capacidade reflexiva dos sujeitos e do conhecimento. Sublinhamos que o conhecimento é um elemento fundante da formação humana. Isto é um desafio histórico posto a cada dia para os debates que permeiam a Educação.

Nesse debate, é oportuno observar as considerações de Nunes (2000), que retoma as formulações de Kant sobre a teoria do belo. Segundo o autor, a filosofia kantiana aponta para duas fontes de conhecimento: a sensibilidade e o entendimento. Segundo as formulações de Kant, seria por meio da sensibilidade que percebemos os objetos, cujas representações, por sua vez, correspondem às percepções dos sentidos, no espaço e no tempo. Para Kant, ainda de acordo com Nunes (2000), essas maneiras de sentir fundamentam as percepções e geram a experiência sensível. As percepções ou intuições constituem-se como matéria-prima do conhecimento. Fazendo uso dos sentidos, o pensamento delimita e organiza a experiência empírica, levando ao entendimento e à formação de conceitos. Assim, quando as intuições da sensibilidade se ajustam aos 
conceitos do pensamento e estes elucidam a experiência sensível, o conhecimento se efetiva. Nunes (2000) conclui que para o filósofo, do século XVIII, o conhecimento está condicionado pelas formas de sentir e pensar, por conseguinte, é fruto da elaboração dessas percepções de nosso espírito.

Ainda a esse respeito, ou seja, sobre a importância da percepção para a efetivação do conhecimento, destacamos a relação entre o olho (instrumento mais universal) e a imagem (objeto cultural e histórico), feita por Aumont (1993) em sua obra A Imagem. No primeiro capítulo, o autor aborda desde as transformações ópticas, químicas, nervosas do sistema visual, perpassando por elementos da percepção até as razões para a produção de imagens. 0 autor, em suas análises, afirma que ao lado do pensamento verbalizado, formado e manifestado pela linguagem, existe o pensamento sensorial, que se organiza com base nos perceptos dos nossos órgãos dos sentidos. Nesse pensamento sensorial, o pensamento visual ocupa um lugar de destaque. 0 da visão é o mais intelectual, o mais próximo do pensamento.

Nesse debate, faz-se relevante acrescentarmos algumas formulações de Hegel (1996). Observa-se que os sentidos da visão e da audição desempenham papel primordial na apreciação do belo artístico. Segundo o autor, o belo manifesta-se especialmente por meio desses dois sentidos, de acordo com uma espécie de visão interior, mais próxima do sentimento do que da razão. Hegel (1996, p. 9) destaca, nesse sentido, que “[...] Temos na arte um particular modo de manifestação do espírito; dizemos que a arte é uma das formas de manifestação porque o espírito, para se realizar, pode servirse de múltiplas formas". Para o autor, a arte, dessa forma, suscita em nós sensações agradáveis, cujo fim último é despertar a alma:

[...] o conteúdo da arte compreende todo o conteúdo da alma e do espírito, que o fim dela consiste em revelar à alma tudo o que a alma contém de essencial, de grande de sublime, de respeitos, a experiência da vida real [...] a arte cultiva o humano no homem [sic], desperta sentimentos adormecidos, põe-nos em presença dos verdadeiros interesses do espírito. [...] Produz a arte todos os seus efeitos mediante a intuição e a representação, [...] 0 importante é que o conteúdo que temos perante nós desperte-nos sentimentos, tendências e paixões, e nos é completamente indiferente que tal conteúdo seja dado pela representação ou que o conheçamos por uma intuição que tivemos na vida real. [...] todas as paixões, o amor, a alegria, a cólera, o ódio, a piedade, a angústia, o medo, o respeito, a admiração, o sentimento da honra, o amor da glória etc podem invadir nossa alma [...] a fim de que as experiências da vida não nos apanhem insensíveis e a nossa sensibilidade permaneça aberta a tudo quanto ocorre fora de nós. [...]. (Hegel, 1996, p. 32-34).

Mediante nosso entendimento desse excerto, podemos observar até que ponto a arte age sobre a nossa maneira de sentir e de pensar. É no processo interior que sua 
eficácia se faz sentir. Ela nos dá a possibilidade para a ação prática. A arte pode despertar sentimentos bons e sentimentos ruins. A arte constitui-se como espelho. Ela coloca o ser humano frente àquilo que ele é, para que assim se conscientize de sua própria natureza, de sua selvageria ou do domínio de seus instintos. Desse modo, a arte nos permite conter certos sentimentos humanos, inapropriados para o bem viver social. Ao colocar o ser humano diante de seus instintos, como se estes the fossem exteriores, a arte dá a ele a oportunidade de se libertar. Os sentimentos que se apossam do ser humano por inteiro, ao passar para a representação, ao se exteriorizar, tanto podem se suavizar, perder a intensidade, quanto se avivar. Podemos, então, por meio de nosso livre arbítrio, escolher o que converge para o bem; fazer uso de nossa liberdade para refrear instintos que divergem do bem. A ação moral deve combater, constantemente, a vontade natural, para que se viva bem coletivamente. Nesse sentido, podemos entender que a arte contribui para a educação dos instintos, ela age com um estímulo externo que ocasiona uma mudança interna, a qual, por sua vez, é refletida nas ações do ser humano.

Nesses termos, é válido considerar que, segundo Nunes (2000), a arte, como produto da práxis cotidiana, é uma forma de ação que traz em si a potencialidade de influir nas atitudes humanas. Desvenda-nos o humano, propiciando a sua interiorização e assimilação à experiência, agindo, assim, sobre a nossa forma de agir e de pensar. Consideremos suas palavras:

As grandes, autênticas e legítimas obras de arte possuem capacidade de atrair a consciência e de fazê-la aderir ao que instantaneamente revelam. [...] dilatando a consciência, tornando-a mais receptiva aos contrastes da vida, ela pode abrir possibilidades para a ação prática. Sem conduzir diretamente nem ao compromisso moral nem à atividade de caráter social ou político, é uma forma de apelo, de solicitação, capaz de despertar a consciência moral para a descoberta dos valores éticos, inclusive os sociais e políticos. (Nunes, 2000, p. 88).

Para o autor, portanto, a arte não tem um fim moralizante determinado; muitas vezes, pode até se contrapor a padrões morais convencionados. Assim, embora não considere conveniente despojá-la de fins éticos e afastá-la da realidade, afirma que, por ser ampla, abarcando o mundo criado pelo artista, ela revela as potencialidades do ser humano, proporcionando-lhe uma visão mais clara e compreensiva do contexto histórico em que foi produzida. Dito de outra forma, nas palavras do autor, "[...] é revelando as possibilidades da consciência moral e não adotando uma moral, que arte cumpre a sua finalidade ética" (Nunes, 2000, p. 89).

Por meio dessa reflexão, podemos verificar que a arte, como uma questão própria da filosofia, contribui para o processo de reflexão a respeito do ser humano e de sua 
participação na totalidade, no universo. Nestes termos, ela tem um papel no processo de humanização.

Cabe aqui considerar os apontamentos de Edgar Morin (2002) sobre a ética do gênero humano. Para ele, a ética se fundamenta na consciência de que o ser humano é, ao mesmo tempo, indivíduo, parte da sociedade e parte da espécie. Assim, para que o desenvolvimento humano ocorra, o sujeito deve, também, buscar a autonomia individual, as participações comunitárias e a consciência de pertencer à espécie humana. É preciso educar com base em valores éticos, estéticos e políticos, possibilitando que o indivíduo elabore sua identidade social e coletiva e contribua para a construção de uma sociedade solidária que vise o bem comum.

Observamos que, em nossa sociedade, falar de fruição, de estético, de valores é relevante. Verifica-se, cada vez mais, a perda da consciência crítica a respeito do contexto em que vivemos, bem como de referenciais éticos e morais. Consideramos que o ser humano não é, por natureza, civilizado, mas possui uma potencialidade para alcançar esse nível. Diante de nossas análises, podemos aceitar que os sentimentos e as sensações que arte gera no ser humano podem direcioná-lo a uma autorregulação de suas ações. Reiteramos, nesse sentido, que entendemos a educação como um fenômeno social que se legitima quando proporciona ao ser humano condições de viver em sociedade. 0 processo de construção e desenvolvimento da sensibilidade humana, que abarca o processo dialético da construção sujeito-mundo, não se dá na individualidade, pois as práticas humanas são coletivas e sociais, em razão disso são históricas.

Torna-se plausível afirmar, nesses termos, que a arte se constitui como uma forma de impedir que nós nos tornemos insensíveis diante do tempo e dos acontecimentos sociais, na medida em que nos mantém sensíveis a tudo o que nos cerca, em especial, o belo.

Enfatizamos, assim, com base nas análises feitas até aqui, que, na perspectiva da Educação e das Ciências Humanas em geral, há uma relação intrínseca entre a arte e a formação humana. Por isso, é importante considerar o fato de que a arte pode despertar a sensibilidade humana, qualidade imprescindível àquele que contribui para o processo de formação do ser humano.

No que concerne à produção da subjetividade, destacamos a importância da imagem como fonte de pesquisa, já que ela possui um duplo caráter: o informativo e o formativo. Sendo histórica e social, ela constitui um sistema de significações específicas que, expressando o ser humano em relação a si próprio, aos demais indivíduos e ao meio em que vive, favorece a reflexão e a ação. Segundo Martins (2007), as imagens influenciam a formação do sujeito - identidade -, articulando representações visuais derivadas de experiências pessoais e visões de mundo que estão presentes nos modelos sociais 
vigentes em uma determinada época ou cultura. Dessa forma, subjetividade e identidade caminham juntas e constituem a consciência de ser sujeito, em um processo dinâmico e múltiplo. As imagens são tratadas como espaço de interação de indivíduos, criando possibilidades de diálogo e interpretação.

Em consonância com a reflexão anterior, apoiamo-nos, novamente, no filósofo Morin (2002), cujos apontamentos nos parecem muito pertinentes. Ele assinala que o enfraquecimento da percepção global conduz ao enfraquecimento da responsabilidade; assim, cada um passa a responder apenas pela sua tarefa, o que desencadeia, também, um enfraquecimento da solidariedade. No contexto das análises concernentes à Educação do século XXI, o autor destaca que é necessário

[...] situar a condição humana no mundo dos conhecimentos derivados das ciências humanas para colocar em evidência a multidimensionalidade e a complexidade humana, bem como integrar (na educação do futuro) a contribuição inestimável das humanidades, não somente a filosofia e a história, mas também a literatura, a poesia, as artes [...]. (Morin, 2002, p. 48).

Um conhecimento articulado traria contribuições para que o ser humano se situasse no mundo, possibilitaria o reconhecimento da unidade e da complexidade humana. Como o ser humano é, a um só tempo, físico, biológico, psíquico, cultural, social e histórico, a História, integrada à arte e a outras áreas do conhecimento, seria uma forma de abranger a totalidade do sujeito, em suas várias dimensões. Uma educação só pode ser eficaz se for uma educação integral do ser humano, uma educação que se dirija à totalidade do ser humano. Desse modo, a condição humana deve ser o objeto essencial de todo o ensino.

Nesses termos, é indispensável que os indivíduos saibam que são parte e construtores da história. Quando eles apreendem o movimento real pela reflexão, podem se reconhecer como sujeitos, como parte de um mundo humanizado, adquirir a compreensão de si e, consequentemente, da realidade e, assim, transformá-la. Salientamos que a nossa época, ou outra qualquer, pode e deve ser modificada por meio de nossas ações. Acreditamos que a leitura de imagens, despertando o senso estético, favorece o desenvolvimento do indivíduo como pessoa sensível, civilizada, culta, solidária, conhecedora, enfim, cidadã.

Diante disso, quanto mais acesso ao mundo da cultura - arte, filosofia e ciência - o ser humano tiver, tanto mais humano ele se fará, mais terá condições de desenvolver e aprimorar sua humanidade. Partimos da premissa de que a arte, assim como todos os demais produtos da criação humana, a exemplo dos costumes, das leis, convenções sociais, mitos, é eminentemente histórica e social, ou seja, nasce na e para a sociedade, 
sendo datada historicamente. Tanto no processo criativo quanto no ato de fruição, ela é uma fonte de humanização e educação do ser humano; por meio de seu universo simbólico, leva-o a formas diferenciadas de sentir, perceber e expressar sensivelmente o mundo e as dimensões humanas (Peixoto, 2001).

Como atividade do espírito e socialmente datada, a arte, além de produzir os objetos artísticos, produz também o artista, um ser que sente, percebe, conhece, reflete e toma posição diante do mundo em que está inserido. Verifica-se que, por meio dela, ao mesmo tempo em que se aprende se educa, bem como se adquire a capacidade para intervir sobre o real; tanto o artista quanto o público fruidor têm possibilidade de se educar, ou seja, crescer e enriquecer-se como seres humanos.

A cultura visual busca compreender o papel social da imagem na vida da cultura, colocando em perspectiva diferentes contextos humanos, povoados por silhuetas de presenças e identidades. As imagens nos constroem como sujeitos em um labirinto de significados que nos interconectam nas dimensões sociais e simbólicas da cultura.

Por tudo isso, nas palavras de Peixoto (2001, p. 137), é possível concordar que o conteúdo das imagens também faz parte da cultura:

[...] a arte em geral e a obra em particular jamais serão neutras, porque sua própria constituição está comprometida com a realidade social e histórica; estão implicados nela um conhecimento relativo e uma tomada de posição do autor frente a esse determinado contexto concreto de vida, ou seja, uma atitude ética e um posicionamento político do indivíduo criador em face das lutas históricas do presente no qual vive, como aprovação ou negação, que são as formas de ele se relacionar com o mundo. Sem esse conjunto de determinações, a obra de arte não terá sostanza para existir [...].

Observamos, pois, que as percepções do social não são discursos neutros. Relacionam-se a estratégias e práticas sociais, educativas, políticas, as quais tendem a estabelecer uma ideia, a legitimar um projeto reformador ou a justificar, para os próprios indivíduos, suas escolhas e condutas.

Nesse aspecto, Nunes (2000) indica que o artista responde às demandas de seu contexto social, às solicitações de sua classe, às vicissitudes morais, sociais e políticas de seu meio datado historicamente. Salientamos, enfim, que não há escolha automática do caminho a ser seguido, pois cada escolha, mediante o nosso livre arbítrio, corresponde a várias possibilidades e responsabilidades. 0 objetivo de fazer prevalecer o bem comum da sociedade supõe renúncias por parte dos indivíduos e do Estado em favor da coletividade. A experiência histórica evidencia que a harmonização dos interesses individuais ou coletivos resultou de uma conquista da vontade ética. Nesse sentido, podemos afirmar que a Educação é a base da formação da sociedade. A abordagem 
proposta neste trabalho decorre desse entendimento da Educação: o do papel fundamental que ela desempenha na formação do ser humano para a vida em sociedade e o de que é essencial aos sujeitos compreender e estabelecer os limites e as ações necessárias para a convivência comum.

Por isso, reportarmo-nos às ideias que Norbert Elias defende em 0 processo civilizador. A ideia-chave das formulações de Norbert Elias (1993, p. 9) é a tese de que a "[...] condição humana é uma lenta e prolongada construção do próprio homem [sic]". Ele entende a civilização como processo, como um civilizar dos costumes. Por isso, um estudo sério do ser humano implica recorrer a uma gama de documentos e ciências, pois "[...] todo e qualquer texto ou mesmo um gesto de um pensador merece, por princípio, a atenção de quem o estuda [...]" (Elias, 1993, p. 9). Em suas formulações há uma dimensão ética, pois ele acredita que o ser humano se civiliza. Como a ação e a decisão do indivíduo são condições essenciais para se alcançar tal objetivo - o desenvolvimento humano -, o autor assinala a importância de se observar, como em um mosaico, a história das ações individuais.

Constatamos, pois, a relevância da formação humana para o desenvolvimento dos indivíduos e da sociedade. Ser capaz de opinar a respeito desse mundo, de expressar a própria vontade e os próprios sentimentos, de entender o outro e de se fazer respeitar, é condição fundamental para ser, de fato, um cidadão.

0 indivíduo deve ser capaz de perceber, refletir, ponderar, sintetizar as informações ofertadas pelo mundo, bem como de elaborar novos conhecimentos sobre esse arcabouço, ser capaz de se deslocar do senso comum para a consciência filosófica, utilizando tudo isso em sua prática social, transformando sua realidade. Para tanto, deve desenvolver sua sensibilidade (Barroco, 2007).

\section{Considerações Finais}

Nas várias reflexões que caracterizam o fenômeno educativo na atualidade, perpassa a ideia de que o mundo contemporâneo exige dos sujeitos sentimentos, conhecimento e sensibilidade que o auxiliem a pensar e agir diante de situações novas. Nossas atitudes devem estar alicerçadas na ética, na moral e nas virtudes. Esses requisitos são desenvolvidos pela capacidade reflexiva dos sujeitos, pelo conhecimento, ou seja, pela autonomia intelectual. Por meio do conhecimento, o ser humano toma consciência do papel que deve desempenhar na sociedade, contribuindo para sua transformação e preservação e também para o desenvolvimento humano.

Elias (1995) sublinha que apreendemos melhor o contexto da nossa própria vida quando nos aprofundamos sobre a vida de sujeitos que pertenceram a outras sociedades. 
De acordo com o autor, as pessoas têm, em potencial, condições de decidir quais valores e juízos querem adotar. Percebemos, assim, uma tendência para esquecer as limitações e as pressões a que nos sujeitamos pelo ato de aceitarmos como 'nossos' os valores e os juízos que preferimos.

Por meio do conhecimento histórico, explicita-se que transformações sociais, quando ocorrem, são realizadas pelos homens, em geral, independente do segmento social. Desse modo, como cabe as pessoas a responsabilidade pelo governo das coisas racionais, particulares e daquelas que convergem para o bem comum, somos levados a refletir sobre os valores, direitos e deveres que devem ser praticados e ensinados. Parece-nos importante rever nossas questões históricas e tentar fazer uso delas em nosso agir cotidiano. Assim, é por meio desses atos que educamos, ensinamos aqueles que nos rodeiam a encontrar novos caminhos.

Enfatizamos, pois, que a sociedade deve ser composta de indivíduos ligados por laços de responsabilidade, de comprometimento, seja em relação a si, seja em relação uns com os outros. Consideramos, que o conhecimento que os sujeitos construíram é que tornou possível a convivência entre eles, ou seja, com base na educação, eles formaram a sociedade em que vivem: suas instituições, crenças, filosofia, arte e ciência.

Nesse sentido, a linguagem imagética, como construção de conhecimento, necessita, para a intelecção de sua sistematização, que o sujeito desenvolva certas competências que $o$ auxiliem a sentir e a significar a obra de arte. Acreditamos que o olhar e o gosto podem ser transformados pelo conhecimento. Quanto mais se conhece mais se aprecia. Essa sensibilidade pode resultar ao ser humano maior entendimento de sua realidade histórica e social, das inquietações e indagações de sua temporalidade. Entendemos que as artes refletem a realidade social e, concomitantemente, trazem em si o potencial da superação dessa realidade. Aceitamos, portanto, a possibilidade concreta de revitalização da sensibilidade como meio de humanizar o ser humano, desenvolvendo nele, além da sensibilidade, a solidariedade, a satisfação em participar de projetos coletivos.

Assinalamos a possibilidade de, por meio da imagem, desenvolver a sensibilidade humana, de educar e humanizar o sujeito na sua totalidade: nos âmbitos sensível, ético e cognitivo. Uma educação que se processa com esse objetivo terá condições de ser mais efetiva. Desse modo, a condição humana deve ser o objeto essencial de todo o ensino. Por meio do conhecimento, o ser humano toma consciência do papel que deve desempenhar na sociedade, contribuindo, por sua vez, seja para a transformação dessa sociedade, seja para a sua preservação e desenvolvimento humano. Postulamos, nessas condições, que o entendimento do mundo pode dar-se pelo entendimento da arte. Para tanto, a sensibilização humana é imprescindível. 


\section{Referências}

AUMONT, Jacques. A imagem. Campinas: Papirus, 1993.

BARROCO, Sonia Mari Shima. Psicologia educacional e arte: uma leitura histórico cultural da figura humana. Maringá: Eduem, 2007.

BLOCH, Marc Léopold Benjamim. Apologia da história: ou ofício do historiador. Rio de Janeiro: Jorge Zahar, 2001.

CASTRO, Hebe. História social. In: CARDOSO, Ciro Flamarion; VAINFAS, Ronaldo (Org.). Domínios da história: ensaios de teoria e metodologia. Rio de Janeiro: Campus, 1997. p. 45-59.

CAUQUELIN, Anne. Teorias da arte. São Paulo: Martins, 2005.

ELIAS, Norbert. O processo civilizador. Rio de Janeiro: Jorge Zahar, 1993. A sociedade de corte. Lisboa: Estampa, 1995.

FRANCASTEL, Pierre. A realidade figurativa: elementos estruturais de sociologia da arte. São Paulo: Perspectiva, 1993.

FONSECA, Selva Guimarães. Didática e prática de ensino de história. Campinas: Papirus, 2006.

HEGEL, Georg Wilhelm Friedric. Curso de estética: o belo na arte. São Paulo: Martins Fontes, 1996.

KERN, Maria Lúcia Bastos. Imagem e acontecimento: o mediterranismo de Joaquín Torres-García. Domínios da Imagem, Londrina, v. 1, n. 1, p. 137-148, nov. 2007.

MARTINS, Raimundo. Educar com imagens: múltiplos tempos e interpretação. Boletim Arte na Escola, São Paulo, n. 45, p. 6-7, abr. 2007. Disponível em: <www.artenaescola.org.br >. Acesso em: 23 out. 2008. MORIN, Edgar. Os sete saberes necessários à educação do futuro. São Paulo: Cortez, 2002.

NUNES, Benedito. Introdução à filosofia da arte. São Paulo: Ática, 2000.

PEIXOTO, Maria Inês Hamann. Relações arte, artista e grande público: a prática estético-educativa numa obra aberta, 2001. 259 f. Tese (Doutorado em História, Filosofia e Educação) - Faculdade de Educação, Universidade Estadual de Campinas - UNICAMP, Campinas, 2001.

Recebida $2^{\text {a }}$ versão em outubro de 2010

Aprovada $2^{\text {a }}$ versão em junho de 2011

Terezinha Oliveira, doutora em História pela Universidade Estadual Paulista Júlio de Mesquita Filho. com estudos de pós-Doutorado em Filosofia da Educação pela USP. Professora do DFE/PPE da Universidade Estadual de Maringá (UEM). Publicações: Conhecimento, intelecto e memória na universidade parisiense: uma leitura tomasiana (Educação e Filosofia (UFU. Impresso), v. 24, p. 7390, 2010). Memória e História da Educação Medieval: uma análise da Autentica Habita e do Estatuto de Sorbonne (Avaliação (UNICAMP), v. 14, p. 683-698, 2009). E-mail:. teleolivagmail.com

Sandra Regina Franchi Rubim, mestre em Educação do PPE da Universidade Estadual de Maringá (UEM). Egressa do PPE e do PDE. Professora da rede pública. Publicações: Dante e o papel do governante no desenvolvimento intelectivo: uma análise da História da Educação. Quidort e a sua contribuição na cisão entre os poderes laico e clerical. Contribuição do pensamento de Egídio Romano na formação das Monarquias Absolutas Européias.E-mail: srfrubimagmail.com 